\title{
Social determinants and adherence to treatment among Colombian women living with HIV/AIDS
}

\author{
Marcela Arrivillaga \\ From International Society for Equity in Health: 6th International Conference 2011 \\ Cartagena, Colombia. 26-28 September 2011
}

\section{Background}

There is a paucity of studies on the social determinants of adherence to antiretroviral therapy, especially in Latin American countries. The purpose of the study was twofold: to assess the relationship between antiretroviral adherence and social position among Colombian women with HIV/AIDS and to examine the possibility of expanding the medical concept of adherence to treatment including a "social determinants of health" perspective.

\section{Method}

A mixed method approach with a qualitative and quantitative sequential design was applied. In the phase of formative research semi-structured interviews were conducted with 7 national experts in the field. The qualitative component of the study included 10 focus groups with a total of 99 women; in-depth interviews were conducted with 14 of these participants. Another 269 women from five different cities completed a socio-demographic and clinical questionnaire, an adherence to treatment questionnaire, and a social position survey designed according to the Colombian socioeconomic structure. Content analyses were applied to analyze the qualitative data and logistic regressions were used to analyze the quantitative data.

\section{Results}

Significant statistical associations and qualitative patterns between adherence and social position were found. Women in a medium and high social position were more likely to present higher adherence behaviors than women in low social position. Also, healthcare system barriers, being a caregiver of children with HIV/AIDS, and individual coping styles were found as critical factors for adherence behaviors.

Correspondence: marceg@javerianacali.edu.co

Department of Public Health \& Epidemiology, Pontificia Universidad Javeriana Cali, Cali, Colombia

\section{Conclusions}

Adherence to treatment in Colombian HIV positive women is determined by their social position. Research on antiretroviral adherence and the concept of adherence itself should include a "social determinants of health" perspective in order to maximize the likelihood of obtaining better clinical outcomes. The findings of the study should also serve as a point of reference for reviewing current healthcare guidelines for people living with HIV/ AIDS in Colombia.

\section{Acknowledgements}

This work was supported by Pontificia Universidad Javeriana Cali and COLCIENCIAS (Colombian Agency for Science and Technology). Author wish to express special appreciation to partners and collaborators in this research effort, including Paula Andrea Hoyos and Diego Correa, Pontificia Universidad Javeriana Cali; Michael Ross and Bernardo Useche, University of Texas, Houston.

Published: 23 January 2012

doi:10.1186/1475-9276-11-S1-A1

Cite this article as: Arrivillaga: Social determinants and adherence to treatment among Colombian women living with HIV/AIDS. International Journal for Equity in Health 2012 11(Suppl 1):A1.

Submit your next manuscript to BioMed Central and take full advantage of:

- Convenient online submission

- Thorough peer review

- No space constraints or color figure charges

- Immediate publication on acceptance

- Inclusion in PubMed, CAS, Scopus and Google Scholar

- Research which is freely available for redistribution

\section{Biomed Central}

(c) 2012 Arrivillaga; licensee BioMed Central Ltd. This is an open access article distributed under the terms of the Creative Commons Attribution License (http://creativecommons.org/licenses/by/2.0), which permits unrestricted use, distribution, and reproduction in any medium, provided the original work is properly cited. 